\title{
A survey of host animals of land leech Haemadipsa zeylanica var. japonica (Whitman) in Akita Prefecture revealed by PCR-SSCP analysis of 28S rRNA genes
}

\author{
Osamu SASAKI ${ }^{1)}$, Hiroyuki SAITO ${ }^{2)}$ and Mariko HARAdA ${ }^{1)}$ \\ 1) Laboratory of Animal Anatomy, Department of Animal Science, Akita Prefectural \\ College of Agriculture, Ohgata, Akita, 010-0444 Japan \\ 2) Akita Prefectural Institute of Public Health, Senshukubota-machi, Akita, 010-0874 Japan
}

(Received: 4 October 2004; Accepted: 9 February 2005)

\begin{abstract}
The host animals of land leech Haemadipsa zeylanica var. japonica (Whitman) were surveyed among nine common mammals in forests and a human by the single strand conformation polymorphism of PCR products of the variable region in the 28S rRNA genes. When the leeches collected in 1995, 1996 and 2000 at Gojome-machi in Akita Prefecture were analyzed, the same banding patterns between the collected leeches and blood samples of the reference animals were only observed in the Japanese serow and copper pheasant or pheasant. The leeches collected in 1995 showed the highest resemblance rate with the serow and it was $86 \%(25 / 29)$, while the leeches collected in 1996 and 2000 showed 34\% (11/32) and 12\% (14/114), resemblance rate respectively. On the other hand, only a few numbers of leeches showed the same banding pattern with the copper pheasant or pheasant. These results indicate that the Japanese serow contributes to the propagation and spread of the leech in Akita Prefecture.
\end{abstract}

Key words: Haemadipsa zeylanica var. japonica, leech, host animal, serow, rDNA, PCR-SSCP

\section{INTRODUCTION}

Since the 1970s, the land leech Haemadipsa zeylanica var. japonica (Whitman) has rapidly expanded in both numbers and habitats around the Dewa hilly region in Akita Prefecture (Enoki and Fujioka, 1993; Sasaki and Tani, 1997) and in other regions, such as Kominato in Chiba Prefecture (Yoshiba, 1988). The massive emergence of this leech caused nuisance to residents and workers in the forest, and is creating hygienic problems by causing serious bleeding. The exact causes of the spread of the leech remain unknown. Control of the leech population in residential quarters was possible by spraying powdered $N, N$-diethyltoluamide (DEET) three to four times during the rainy season with a motor-driven sprayer (Sasaki and Tani, 1997). However, it is important to identify the host animals that contribute to the propagation and spread of the leech, for the control of leech population in the forest.

The 28S ribosomal RNA (rRNA) genes form a tandem repeat structure consisting of conserved and variable regions that are specific to the animal species (Hillis and Dixon, 1991; Raue et al., 1988). Molecular typing with the variable region of the $28 \mathrm{~S}$ rRNA genes has gained substantial taxonomic significance in insects (Varricchio et al., 1995) and fish (Hara et al., 1994).

Furthermore, the applicability of this method to identification of vertebrate species has been demonstrated through fingerprinting of the variable region of $28 \mathrm{~S}$ rRNA genes using single strand conforma- 
tion polymorphism analysis followed by polymerase chain reaction (PCR-SSCP) (Naito et al., 1992; Hara et al., 1994). This technique allows the rapid screening of a large number of specimens.

In this study, fingerprinting of $28 \mathrm{~S}$ rRNA genes was used for identification of the host animals of the leech collected from a forest at Gojome-machi in Akita Prefecture. Based on the band patterns of PCR-SSCP, we were able to confirm the animal species that the leech had fed on in the forest.

\section{Materials AND Methods}

A total of 175 leeches were collected from the forest at Gojome-machi from July to September in 1995, 1996 and 2000, and were stored at $-80^{\circ} \mathrm{C}$ until use.

\section{DNA isolation}

The frozen leeches were sliced into small pieces and these were gently homogenized in TE buffer (10 mM Tris- $\mathrm{HCl}$ and $1 \mathrm{~mm}$ EDTA, pH 8.0), containing 0.5\% SDS with a pellet pestle homogenizer at $4^{\circ} \mathrm{C}$ (Kontes, Vineland, NJ, USA).

Genomic DNA was extracted from the blood of nine wild animals and a human as the reference samples; marten (Martes melampus), Apodemus speciosus, raccoon dog (Nyctereutes procyonoides), Japanese serow (Capricornis crispus), field hare (Lepus brachyurus), copper pheasant (Phasianus soemmerringii), pheasant (Phasianus colchicus versicolor), bear (Selenarctos thibetanus), fox (Vulpes vulpes) and a human.

Total DNA of leeches and blood of the animals were isolated by standard extraction methods using SDS and proteinase K. Briefly, homogenized samples were digested with $0.2 \mathrm{mg} / \mathrm{ml}$ of proteinase $\mathrm{K}$ at $55^{\circ} \mathrm{C}$ for 2 hours. Then, DNAs were precipitated by ethanol after phenol/chloroform extraction, and were resuspended in $\mathrm{TE}$ buffer.

\section{PCR}

Biotin-labeled primers (primer A: 5'-
ATCTAGTAGCTGGTTCCCTC-3'; primer B: 5'-CCTCTAATCATTCGCTTTAC-3') designed to amplify the variable region of 28S rRNA genes were purchased from QUIAGEN (Tokyo) (Naito et al., 1992). PCR was performed in a $50 \mu \mathrm{l}$ reaction mixture containing the following: $0.5 \mu \mathrm{l}$ of template DNA (approximately 1 to $10 \mathrm{ng}$ ); $0.5 \mu l$ of each primer ( $20 \mathrm{pmol}) ; 5 \mu l$ of $10 \mathrm{X}$ PCR buffer; $4 \mu l$ of dNTP mixture $(2.5 \mathrm{~mm})$; $0.5 \mu l$ of $T a q$ polymerase (0.5 units); and 39 $\mu l$ of distilled water. All reagents for PCR were purchased from Takara Shuzo (Tokyo). Amplification was performed in a Minicycler (Funakoshi, Tokyo) with 30 cycles of $94^{\circ} \mathrm{C}$ for 1 minute, $51^{\circ} \mathrm{C}$ for 1.5 minutes and $72^{\circ} \mathrm{C}$ for 1 minute. The PCR products and a size marker of $\lambda$-EcoT $14 \mathrm{I}$ digest were electrophoresed in 1.5\% agarose gels and Tris-acetate-EDTA buffer using a Mupid electrophoresis (Advance, Tokyo) and were visualized by ethidium bromide staining.

SSCP analysis was performed using the method of Orita et al. (1989) with a slight modification. PCR products were diluted 100 -fold in a denaturing solution (95\% formamide- $0.25 \%$ bromophenol blue$0.25 \%$ xylene cyanol) and were denatured at $90^{\circ} \mathrm{C}$ for 2 minutes, then cooled on ice. The samples were immediately applied to SSCP-gel $(28 \times 37 \times 0.35 \mathrm{~cm})$, consisting of $7.86 \%$ acrylamide and $0.16 \%$ bisacrylamide in $90 \mathrm{~mm}$ Tris-borate buffer $(\mathrm{pH}$ 8.3) with $4 \mathrm{~mm}$ EDTA and 5\% glycerol. Electrophoresis was performed at $45 \mathrm{~W}$ for 5 hours at $24^{\circ} \mathrm{C}$ using an electrophoresis apparatus (AE-6160, ATTO, Tokyo).

DNA fragments in the gel were detected using a chemiluminescent detection system based on biotin-streptavidin (Imaging high-Chemilumi, TOYOBO, Osaka). The detection of DNA fragments was performed according to the manufacturer's instructions.

\section{Sequence analysis}

For sequence analysis, DNA fragments amplified from a leech of No. 15 collected in 1996 and a blood sample of the Japa- 
nese serow were separated by $4 \%$ low melting temperature agarose (SeaPlaque Agarose, Takara, Tokyo). DNA fragments observed in the agarose gel were sliced and re-melted in microtubes at $65^{\circ} \mathrm{C}$. DNA fragments were purified by phenol/chloroform, chloroform/isoamylalchol extraction and ethanol precipitation, and then they were treated with T4 DNA polymerase to blunt the terminals and with T4 polynucletide kinase for blunt-end ligation. These DNA fragments were inserted into the Sma I site of pUC18 with T4 DNA ligase and transfected in Escherichia coli, JM109.

Nucleotide sequences were determined by dideoxy chain termination using a Dye Primer Cycle Sequencing kit (Applied Biosystems) and a 373S Sequencer (PerkinElmer Co., Newark, NJ).

\section{RESULTS}

All PCR products of the leeches were electrophoresed in 1.5\% agarose gel and were recognized as a single band by $74 \mathrm{bp}$ of the marker (Fig. 1).

On the other hand, many leeches collected in 1995 and 1996 and the blood samples of 10 animal species showed different patterns on SSCP of the 28S rRNA genes analysis, as shown in Figs. 2 and 3 . In SSCP analysis, two bands specific for the Japanese serow and three bands specific for the pheasant or copper pheasant were observed in many leeches. In addition, the pheasant or copper pheasant, and marten and raccoon dog showed very similar patterns in SSCP, respectively.

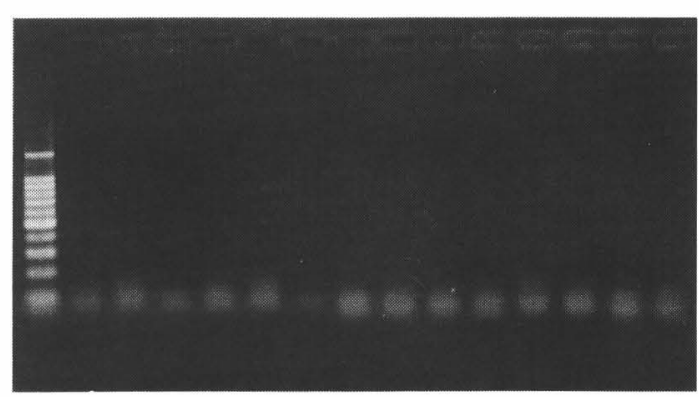

Fig. 1. Gel electrophoresis of PCR products from fourteen leeches collected in 1996 with a marker.

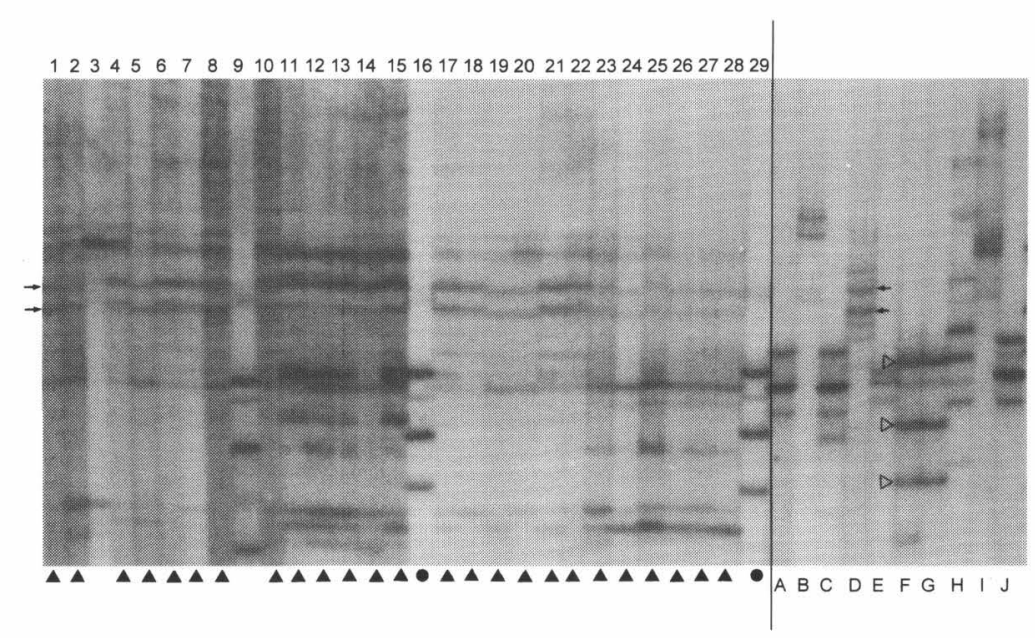

Fig. 2. PCR-SSCP electrophoretic patterns of twenty-nine leeches collected in 1995 and the reference controls of ten animal species including a human. A, Marten (Martes melampus); B, Apodemus speciosus; C, Raccoon dog (Nyctereutes procyonoides); D, Japanese serow (Capricornis crispus); E, Field hare (Lepus brachyurus); F, Copper pheasant (Phasianus soemmerringii); G, Pheasant (Phasianus colchicus versicolor); H, Bear (Selenarctos thibetanus); I, Human; J, Fox (Vulpes vulpes). The arrows show specific bands observed in Japanese serow. The arrowhead indicates specific bands observed in copper pheasant and pheasant. The leeches showing the same bands with Japanese serow or copper pheasant and pheasant are labelled with filled triangles or circles, respectively. 


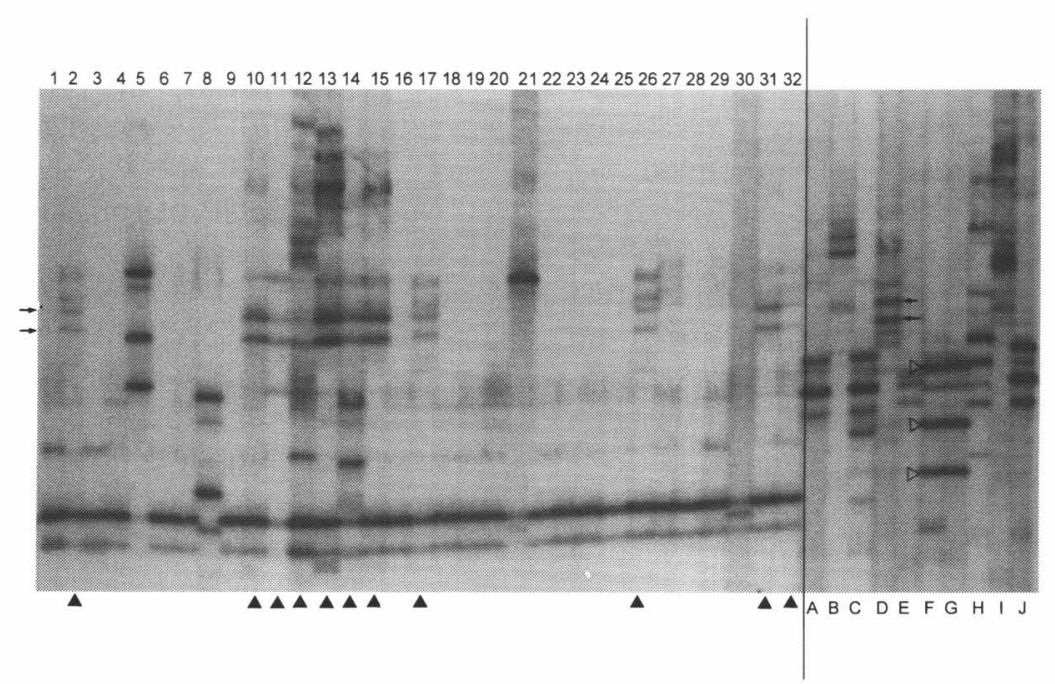

Fig. 3. PCR-SSCP electrophoretic patterns of 32 leeches collected in 1996 and the reference controls of ten animal species. See the legend of Fig. 2 for details.

Table 1. Animal blood positive leeches, Haemadipsa zeylanica var. japonica (Whitman) on the basis of PCR-SSCP analysis of the 28S rRNA genes.

\begin{tabular}{|c|c|c|c|}
\hline \multirow{2}{*}{ Animals } & \multicolumn{3}{|c|}{ Years } \\
\hline & 1995 & 1996 & 2000 \\
\hline Marten & 0 & 0 & 0 \\
\hline Apodemus speciosus & 0 & 0 & 0 \\
\hline Raccoon dog & 0 & 0 & 0 \\
\hline Japanese serow & $25(86 \%)$ & $11(34 \%)$ & $14(12 \%)$ \\
\hline Hare & 0 & 0 & 0 \\
\hline Copper pheasant or pheasant & $2(7 \%)$ & 0 & $3(3 \%)$ \\
\hline Bear & 0 & 0 & 0 \\
\hline Human & 0 & 0 & 0 \\
\hline Fox & 0 & 0 & 0 \\
\hline Total number of leeches examined & 29 & 32 & 114 \\
\hline 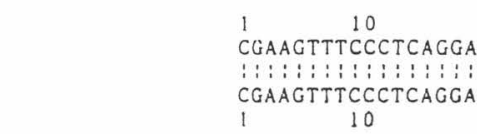 & 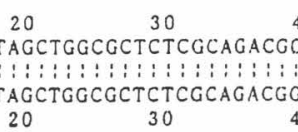 & $\begin{array}{l}50 \\
\text { ACGCAGTTTTA } \\
\vdots: \vdots: \vdots: \vdots: \vdots: \\
\text { ACGCAGTTTTA } \\
50\end{array}$ & \\
\hline
\end{tabular}

Fig. 4. Comparison of nucleotide sequences of 28S rRNA genes fragments amplified from a leech of No. 15 collected in 1996 (upper) and a Japanese serow (lower).

Frequency of leeches showing the specific bands of the Japanese serow was variable in samples collected in 1995, 1996 and 2000 , and it was $86 \%, 34 \%$ and $12 \%$, respectively (Table 1). Only two and three leeches which showed the same pattern with the pheasant or copper pheasant were detected in 1995 and 2000, respectively (Fig. 2).
The sequence of the PCR product of a leech collected in 1996 showed the same pattern with the Japanese serow (Fig. 4).

\section{Discussion}

We detected two specific bands of the Japanese serow in the collected leeches by PCR-SSCP analysis of the variable region 
of $28 \mathrm{~S}$ rRNA genes in 3 different years (Figs. 2, 3, Table 1). These bands exhibited the highest detection rate in the present study, varying from $86 \%, 34 \%$ and $12 \%$ in the different years. These results suggest that at least the Japanese serow is a good host and transporter of the leech among ten species of animals including humans in Akita Prefecture. Since the detection rate of the serow is not so high, other animals may be involved in spreading of the leech.

The sika deer (Cervus nippon) has similarly been considered as a suitable host animal for leech infestation in the Boso peninsula (Asada et al., 1995; Yoshiba, 1988, 1989; Yoshiba and Abe, 1989; Yoshiba and Ishii, 1992a, b). Furthermore, $40 \%$ of the examined sika deer had formed interdigital tumors as a result of feeding leeches and the tumor-bearing ratio varied in the density of leech population (Asada et al., 1995). Although the exact reason for the spread of the leech in Akita Prefecture remains unknown, the increase in numbers and habitats of the leech appears to be occurring in a similar manner as for the sika deer; the formation of interdigital tumors or adhesion to nose or anus of the Japanese serow, depending on the density of fur cover (Asada et al., 1995; Yoshiba, 1989; Yoshiba and Ishii, 1992b). Furthermore, it is important to analyze the correlation between the spread of the leech and the increment of population of the Japanese serow, because the serows were designated as a protected species in 1955 around the Dewa hilly region in Akita Prefecture. Since many bands of the leeches were not shared with the reference samples in SSCP analysis, the leeches may suck other host animals. Although, there is no report on the overlapping of habitats of the leech and the Japanese serow, the serow appears to be an important host animal for the leech in Akita Prefecture.

In the meantime, many species of forest animals are a potential source for the leech for blood feeding. As reported previ- ously (Yoshiba, 1988, 1989; Yoshiba and Abe, 1989; Yoshiba and Ishii, 1992b), wild macaque (Macaca fuscata) and rabbit (Lepus brachyurus) had been identified as host animals of the leeches which sucked from the anus and auricula. However, immunohistological studies of the leeches collected at Kominato in Chiba Prefecture, showed that the leeches have sucked blood from sika deer rather than wild macaque and rabbit (Yoshiba and Ishii, 1992b). Since small animals like mice easily can remove sucked leeches, the animals seem not to be suitable hosts for blood feeding.

Furthermore, leeches had experimentally sucked blood from frogs, geckos, newts, caterpillars of sphinix moths and locusts, and it remains unclear whether the poikilothermal animals and insects are available hosts for the spread of leech or not, because there is no report of leeches feeding from those animals in the field.

We also detected a small number of leeches having three specific bands with copper pheasant and pheasant in the present study (Fig. 2, Table 1). Wild pigeons are known as good hosts for leeches by experimental infection and leeches can suck blood from the palpebra, feet or base of the wing without being removed (Yoshiba and Ishii, 1992b). Therfore, adhering to wild birds may be the most important for propagation and spread of leeches.

We found that leeches collected in Akita Prefecture sucked blood from the Japanese serow, compared with the reference animals (Figs. 2, 3, Table 1). The reason why the detection rate of the Japanese serow in 1995 was the highest among three different years is not clear. The detection rate may be different in the collecting sites of leeches. Therefore, the high rate $(86 \%)$ of host animals of the Japanese serow in 1995, may be attributed to the resting area of the serows suspected by local residents. In contrast, the leeches were collected from various sites in the forest of Gojome-machi in 1996 and 2000, 
hence the leeches might show a lower rate as host animal of the serow than that observed in 1995.

\section{REFERENCES}

Asada, M., Ochiai, K. and Yamanaka, I. 1995. Parasitic state of land leech on sika deer on the Boso peninsula, central Japan. J. Nat. Hist. Mus. Inst. Chiba, 8: 217-221 (In Japanese).

Enoki, H. and Fujioka, H. 1993. Damages by the land leech (Haemadipsa zeylanica japonica) in Akita Prefecture. Tohoku Branch Jpn. Forestry Soc., 45: 61-62 (In Japanese).

Hara, M., Noguchi, M., Naito, E., Dewa, K. and Yamanouchi, H. 1994. Ribosomal RNA gene typing of fish genomic using PCR-SSCP method. Bull. Jpn. Sea Natl. Fish. Res. Inst., 44: 131-138 (In Japanese). Hillis, D. M. and Dixon, M. T. 1991. Ribosomal DNA: molecular evolution and phylogenetic inference. Q. Rev. Biol., 66: 411-453.

Naito, E., Dewa, K., Yamanouchi, H. and Kominami, R. 1992. Ribosomal ribonucleic acid (rRNA) gene typing for species identification. J. Forensic Sci., 37: 396-403.

Orita, M., Iwahana, H., Kanazawa, H., Hayashi, K. and Sekiya, T. 1989. Detection of polymorphisms of human DNA by gel electrophoresis as singlestrand conformation polymorphisms. Proc. Natl. Acad. Sci. USA, 86: 2766-2770.

Raue, H. A., Klootwijk, J. and Musters, W. 1988. Evolutionary conservation of structure and function of high molecular weight ribosomal RNA. Prog. Biophys. Mol. Biol., 51: 77-129.

Sasaki, O. and Tani, S. 1997. Chemical and biological control of land-dwelling leech, Haemadipsa japoni- ca. Med. Entomol. Zool., 48: 303-309.

Varricchio, P., Gargiulo, G., Graziani, F., Manzi, A., Pennacchio, F., Digilio, E., Tremblay, E. and Malva, C. 1995. Characterization of Aphidus ervi (Hymenoptera, Braconidae) ribosomal genes and identification of site-specific insertion elements belonging to the non-LTR retrotransposon family. Insect Biochem. Mol. Biol., 25: 603-612.

Yoshiba, S. 1988. Preliminary report on a mass occurrence of the land leech, Haemadipsa zeylanica japonica Whitman, 1886, in Kominato, Chiba Prefecture and their medical-zoological characteristics. Annu. Rep. Inst. Marine Ecosystem, No. 8: 4551 (In Japanese).

Yoshiba, S. 1989. Physiology, ecology and the field experiment on extermination of the land leech, Haemadipsa zeylanica japonica, that explosively propagated in Kominato, Chiba Prefecture. Annu. Rep. Inst. Marine Ecosystem, No. 9: 52-62 (In Japanese).

Yoshiba, S. and Abe, M. 1989. Immunohistochemical identification of vectors on a mass occurrence of the land leech, Haemadipsa zeylanica japonica in Kominato, Chiba Prefecture. Jpn. J. Hyg., 44: 452452 (In Japanese).

Yoshiba, S. and Ishii, M. 1992a. Anti-land leech antibody production in human and mammalian animals and its killing effect on land leech, Haemadipsa zeylanica japonica Whitman, 1886 . -An immunological mechanism to control the population-. Annu. Rep. Inst. Marine Ecosystem, No. 12: 61-64 (In Japanese).

Yoshiba, S. and Ishii, M. 1992b. Antibody production against injured person by the leech, Haemadipsa zeylanica japonica and identification of vectors. Jpn. J. Hyg., 47: 158-158 (In Japanese). 